\title{
Ring-opening (co)polymerization of $\gamma$-butyrolactone: a review
}

\author{
Qilei Song, ${ }^{\dagger}$ Junpeng Zhao,${ }^{\dagger}$ Guangzhao Zhang,${ }^{\dagger}$ Frédéric Peruch, ${ }^{*}$, Stéphane Carlotti, ${ }^{*}$
}

${ }^{\dagger}$ Faculty of Materials Science and Engineering, South China University of Technology, Guangzhou 510640, People's Republic of China

Univ. Bordeaux, CNRS, Bordeaux INP, LCPO, UMR 5629, F-33600, Pessac, France

* Corresponding author E-mail: peruch@enscbp.fr, carlotti@enscbp.fr

\section{ABSTRACT}

With increased environment concerns and the rising demands for sustainable polymers, e.g. degradable polymers and chemically recyclable polymers, studies on ring-opening polymerization (ROP) of cycle esters have been developed during last decades. Biorenewable five-membered $\gamma$-butyrolactone $(\gamma \mathrm{BL}$ ) could be a desirable feedstock for the chemical synthesis of poly( $\gamma$-butyrolactone) ( $\mathrm{P} \gamma \mathrm{BL}$ ) or for the incorporation of $\gamma \mathrm{BL}$ units into polyester chains in order to modify their properties. Although $\gamma \mathrm{BL}$ is traditionally considered to be "nonpolymerizable", some progresses were recently made in ROP of $\gamma \mathrm{BL}$. This mini-review is thus specially focused on the ROP of $\gamma \mathrm{BL}$ and its copolymerization with other cyclic esters.

\section{KEYWORDS}

$\gamma$-butyrolactone; polyester; ring-opening polymerization

GRAPHICAL ABSTRACT

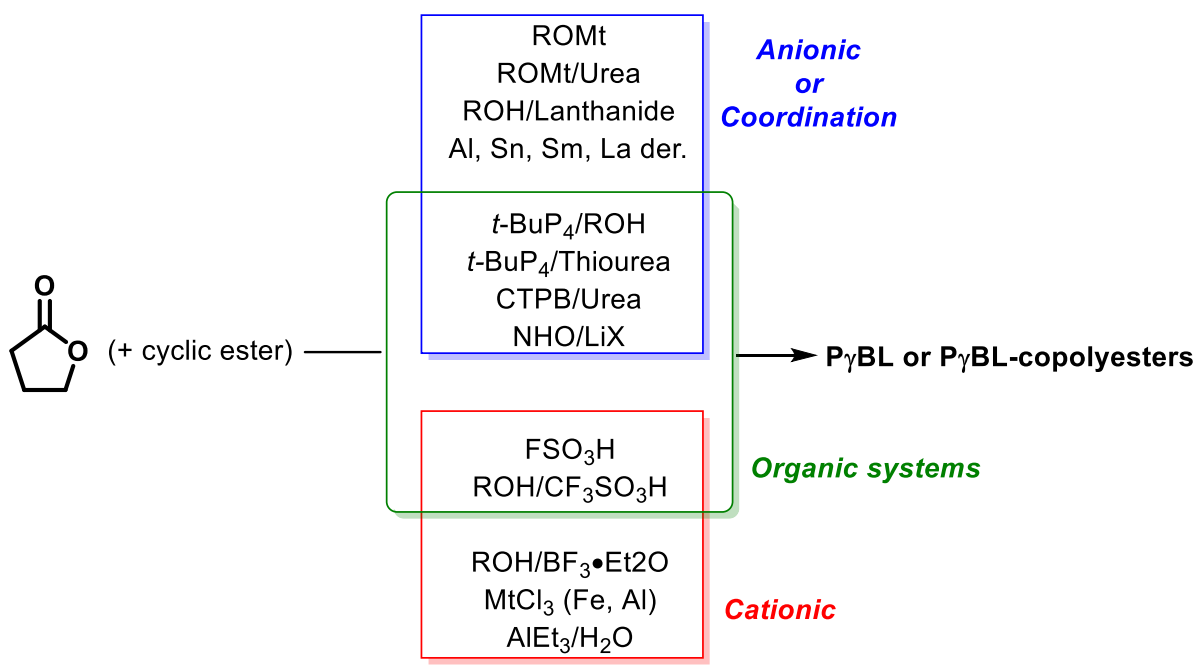




\section{INTRODUCTION}

Aliphatic polyesters are a compelling class of polymers considering their widespread applications in different areas, thanks to their biodegradability and biocompatibility. ${ }^{1-4}$ They can be obtained either by polycondensation of diols with diacids or diesters, of hydroxyesters or hydroxyacids, or by ring-opening polymerization (ROP) of cyclic esters. The latter has been demonstrated to be a powerful strategy to synthesize polyesters with various macromolecular architectures and properties in a controlled manner. ${ }^{5-8}$ Among the diversity of lactones, the fivemembered $\gamma$-butyrolactone $(\gamma \mathrm{BL})$, a renewable monomer derived from succinic acid, ranked as a top biomass-derived chemical, could be an alternative for the chemical synthesis of biopolyester, poly $(\gamma$-butyrolactone) ( $\mathrm{P} \gamma \mathrm{BL})$, a structural equivalent of poly(4-hydroxybutyrate) (P4HB), which is obtained from a bacterial fermentation process. ${ }^{9}$ Moreover, it was demonstrated that the incorporation of $\gamma \mathrm{BL}$ into polyesters resulted in an enhanced biodegradability and flexibility. ${ }^{10}$

Compared to the commonly utilized lactones having high strain energy, $\gamma \mathrm{BL}$ is traditionally considered as "non-polymerizable", due to the low strain energy of the five-membered ring that brings a too small negative change of enthalpy $\left(\Delta H_{\mathrm{p}}\right)$ to overcome a large negative entropic change $\left(\Delta S_{\mathrm{p}}\right)$ of its ROP. ${ }^{11-14}$ It is then difficult to obtain high molar mass $\mathrm{P} \gamma \mathrm{BL}$ via a simple chemical synthesis process. As early as the 30 s to the 50 s, attempts to polymerize $\gamma$ BL revealed unsuccessful. ${ }^{15,16}$ In the $60 \mathrm{~s}$, oligomers of $\mathrm{P} \gamma \mathrm{BL}$ were synthesized under extreme reaction conditions (e.g. 20,000 atm, $160{ }^{\circ} \mathrm{C}$ ) or through catalysis with Lewis acid for long reaction time. ${ }^{17}$ Thus, ROP of $\gamma \mathrm{BL}$ under mild conditions remained a challenge in polymer synthesis for decades. Since a couple of years, there is a breakthrough in ROP of $\gamma$ BL, which can now be performed at low temperature (below the ceiling temperature $\left(T_{\mathrm{c}}\right)$ ) and high monomer concentration, to yield high molar mass $\mathrm{P} \gamma \mathrm{BL}$ with linear or cyclic structures. ${ }^{18-24}$ Ring-opening copolymerization (ROCP) of $\gamma \mathrm{BL}$ and other lactones with high ring strain energy (or cyclic ether) is another pathway to avoid its "non-polymerizability" (Fig. 1). Several examples have been described with different catalysts under varied conditions.

In this mini-review, we thus intend to summarize the studies and results on ROP and ROCP of $\gamma \mathrm{BL}$. The different catalysts described in the literature will be presented and the recent progress will be emphasized. A variety of metal-based systems and organic compounds are employed as catalysts/initiators in ROP/ROCP of $\gamma \mathrm{BL}$ (Fig.2), which can be classified as alkali metal bases, other organometallics, organic bases, Lewis acids and Brønsted acids. Bimolecular catalytic systems which consist of both an acid (or hydrogen donating) and a basic (hydrogen accepting) component have also been utilized for the synthesis of P $\gamma \mathrm{BL}$. Up to now, for the systems mentioned above, lanthanides, organic bases and different acid-base pairs are proved to be most efficient initiator/catalyst systems for ROP/ROCP of $\gamma \mathrm{BL}$, all of them are performed at low temperature and high monomer concentration. 
Cyclic esters<smiles>CC(C)C1CC(=O)O1</smiles><smiles>O=C1COC(=O)CO1</smiles><smiles>CC1OC(=O)C(C)OC1=O</smiles><smiles>O=C1CCCCC1C1CCCCC1</smiles><smiles>O=C1CCCCC1</smiles>

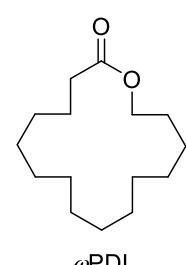

Cyclic ether

Fig. 1 Representative comonomers used in ROCP with $\gamma \mathrm{BL}$

5

6

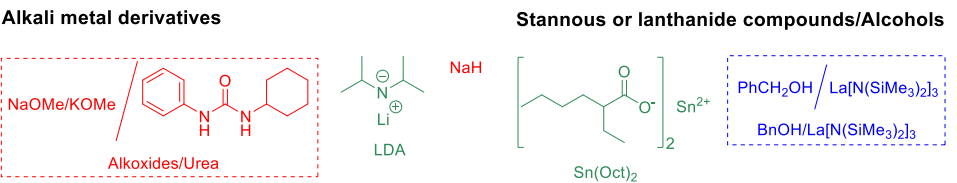

Organometallic compounds and lanthanides
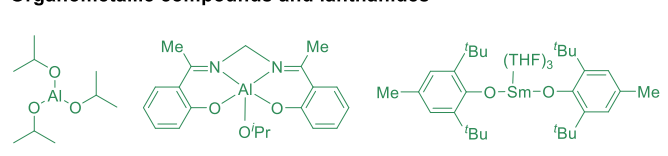

$\mathrm{Al}\left(\mathrm{O}^{\mathrm{Pr}}\right)_{3}$

HAPENAIO'Pr
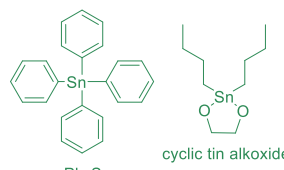

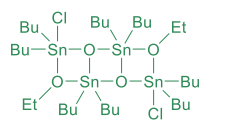

$\mathrm{Sm}(\mathrm{OAr})_{2}\left(\mathrm{THF}_{3}\right.$ $\mathrm{Ph}_{4} \mathrm{Sn}$
$\mathrm{Me}_{3} \mathrm{Si} \quad \mathrm{SiMe}_{3}$

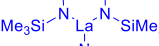
$\mathrm{Me}_{3} \mathrm{Si}^{-}{ }^{-}-\mathrm{SiMe}_{3}$ $\mathrm{La}\left[\mathrm{N}\left(\mathrm{SiMe}_{3}\right)_{2}\right]_{3}$
Organic bases and acid-base pairs

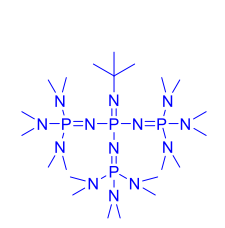

$t$-BuP

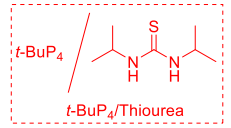<smiles>ClCC1(CCl)COC1</smiles>

BCMO

Lewis acids and Brønsted acids

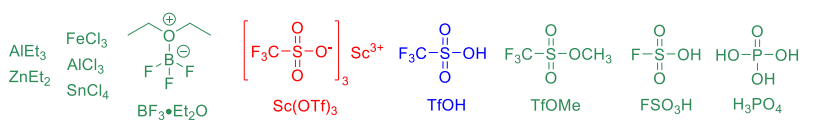

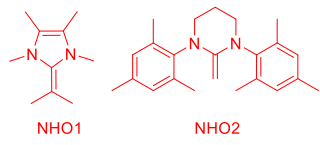

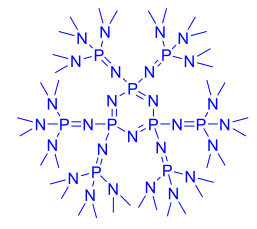

CTPB

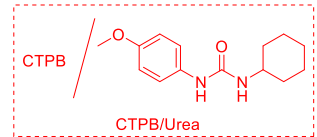

Fig. 2 Representative initiators/catalysts for ROP/ROCP of $\gamma \mathrm{BL}$ (those in red were only used for ROP of $\gamma \mathrm{BL}$, those in blue were used for ROP and ROCP of $\gamma \mathrm{BL}$, and those in green were

$$
\text { only used for ROCP of } \gamma \mathrm{BL} \text { ) }
$$




\section{RESULTS AND DISCUSSION}

\section{$1 \quad$ Alkali metal derivatives as initiators}

Low reaction temperature and high monomer concentration are favorable for the ROP of $\gamma \mathrm{BL}$ due to the low ceiling temperature $\left(T_{\mathrm{c}}\right)$ of such a monomer. The bulk polymerization of $\gamma \mathrm{BL}$ was shown to proceed at $-40{ }^{\circ} \mathrm{C}$ using potassium or sodium methoxide (MtOMe) with low monomer conversions up to $25 \%$ after a few hours. ${ }^{23}$ Working in tetrahydrofuran (THF) at -50 ${ }^{\circ} \mathrm{C}$ was even worse as only $4 \%$ conversion was reached. ${ }^{25}$ PEG- $b$-P $\gamma$ BL block copolymers could be also prepared in low yields starting from poly(ethylene glycol) macroinitiator deprotonated by $\mathrm{NaH}$ followed by polymerization of $\gamma \mathrm{BL}$ in dichloromethane/THF (DCM/THF) mixture. This copolymerization was actually working at room temperature due to the presence of the second cyclic ester which is mandatory to stop any backbiting reaction. ${ }^{26}$ Lithium diisopropylamide in dioxane was also shown to copolymerize at $25{ }^{\circ} \mathrm{C} \varepsilon$-caprolactone $(\varepsilon \mathrm{CL})$ and $\gamma \mathrm{BL}$ with up to $26 \%$ incorporation of the second monomer into the copolymer after ringopening. ${ }^{27}$

Adding ureas to $\mathrm{NaOMe}$ enhanced the reactivity of the active species making the polymerization feasible in bulk at $-20{ }^{\circ} \mathrm{C}$ with up to $70 \%$ monomer conversion in 2 hours. ${ }^{23}$ Using KOMe with various ureas in THF at $-50{ }^{\circ} \mathrm{C}$ was less efficient in terms of monomer conversion. ${ }^{25}$ In any case, urea anion is believed to both activate the alcohol initiator and $\gamma \mathrm{BL}$ before the polymerization following an anionic mechanism (Scheme 1). Such type of binary catalysts achieved better ROP control and monomer conversions than alkali metal alkoxides alone. Moreover, alkaline urea bearing electron-donating groups are exhibiting the lower activation barrier according to thermodynamic calculation, and should possess a higher reaction efficiency. $^{23}$

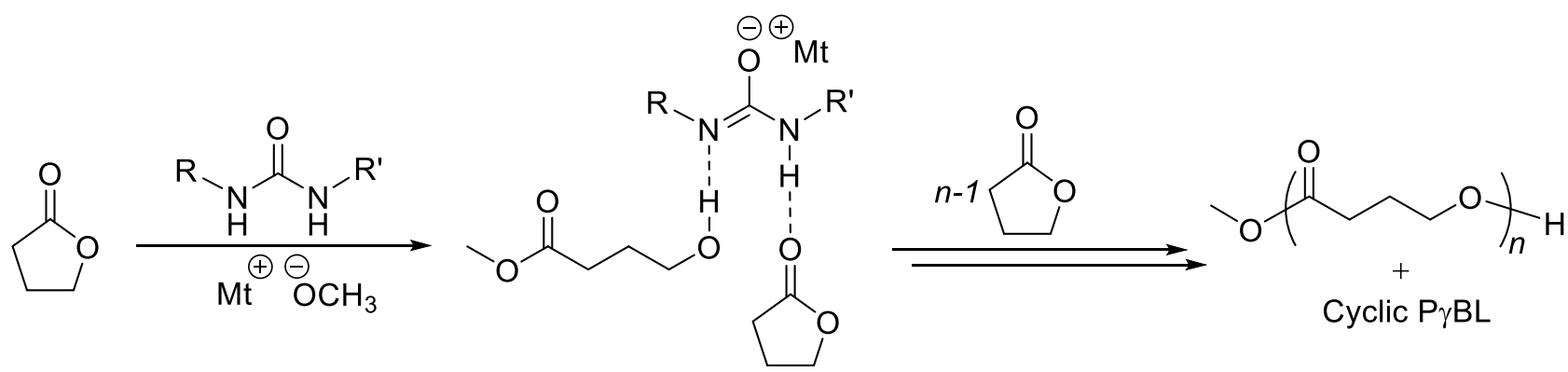

Scheme 1: ROP of $\gamma$ BL by a metal alkoxide/urea system ${ }^{23}$

\section{Stannous or lanthanide compounds associated to alcohols}

Tin(II) octanoate $\left(\mathrm{Sn}(\mathrm{Oct})_{2}\right)$ in the presence of ethanolamine was used to synthesize poly $(\varepsilon-$ caprolactone) including randomly distributed $\gamma \mathrm{BL}$ units $(16 \mathrm{~mol} \%)$. It was shown that both the $-\mathrm{OH}$ and $-\mathrm{NH}_{2}$ groups of the ethanolamine were linked to the Sn center forming a new complex able to perform the copolymerization initiated by those 2 functions (Scheme 2). ${ }^{27}$ This result is 
suggesting an anionic ring-opening polymerization process comparable with the nucleophilic mechanism observed with alkali metal alkoxides used as initiators.

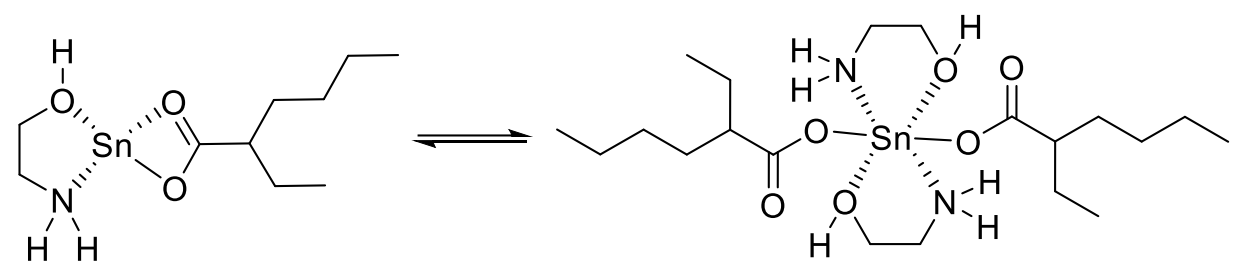<smiles>O=C1CCCCOC1C1CCCCO1</smiles><smiles>[Y]C(C)(C)OC(C)C(=O)OCCN</smiles>

Scheme 2: Ethanolamine-initiated ROCP of $\varepsilon \mathrm{CL}$ and $\gamma \mathrm{BL}$ catalyzed by $\mathrm{Sn}(\mathrm{Oct}) 2^{27}$

In the same vein, $\mathrm{ROP}$ of $\gamma \mathrm{BL}$, that employed benzyl alcohol $\left(\mathrm{PhCH}_{2} \mathrm{OH}, \mathrm{BnOH}\right)$ as initiator, $\operatorname{tri}\left[N, N\right.$-bis(trimethylsilyl)amide] lanthanum(U) $\left(\mathrm{La}\left[\mathrm{N}\left(\mathrm{SiMe}_{3}\right)_{2}\right]_{3}\right)$ as catalyst, and high concentration of $\gamma \mathrm{BL}$, was achieved in THF at $-40{ }^{\circ} \mathrm{C}$ with a yield up to $43 \%$ in half a day (Scheme 3). ${ }^{18}$ Linear and cyclic $\mathrm{P} \gamma \mathrm{BL}$ structures were shown to co-exist and to depend on the catalyst/initiator ratio. Intramolecular back-biting occurs in the $\mathrm{La}-\mathrm{OCH}_{2} \mathrm{Ph}$-initiated $\mathrm{ROP}$, but in a much lesser extent than the ROP initiated by $\mathrm{La}-\mathrm{N}\left(\mathrm{SiMe}_{3}\right)_{2}$ alone which will be discussed in the next section. Effective copolymerization of $\gamma \mathrm{BL}$ with $\varepsilon \mathrm{CL}$ and $\delta$-valerolactone $(\delta \mathrm{VL})$ at low temperatures yielded a series of relatively high molar mass copolyesters with high levels of $\gamma \mathrm{BL}$ incorporation (8 to $84 \%$ ). ${ }^{28}$ The copolyesters exhibited random structure with a high content of $\gamma \mathrm{BL}$.

\section{Organometallic compounds and lanthanides as catalysts}

Organometallic compounds and lanthanides were also proposed without any addition of protic species. A coordination-insertion mechanism is thus expected. Tentative copolymerization of $\gamma \mathrm{BL}$ with glycolide or $\beta$-propiolactone $(\beta \mathrm{PL})$ were performed using zinc chloride $\left(\mathrm{ZnCl}_{2}\right)$ or aluminum isopropoxide $\left(\mathrm{Al}\left(\mathrm{O}^{i} \mathrm{Pr}\right)_{3}\right)$ without real success. ${ }^{29,30} \mathrm{Using}$ aluminum isopropoxide trimer at room temperature, in the 90s Penczek and Duda could prepare poly( $\varepsilon$-caprolactoneco- $\gamma$-butyrolactone) copolymers with molar masses up to $30000 \mathrm{~g} / \mathrm{mol}$ and containing up to 43 
mol\% of $\gamma \mathrm{BL}$ repeating units. Noteworthy, the molar masses were controlled by the concentrations of the consumed comonomers and the starting concentration of the aluminum initiator. $^{31-33}$

Tetraphenyl tin catalyst revealed its efficiency at $140{ }^{\circ} \mathrm{C}$ for preparing statistical poly $(\gamma$ butyrolactone-co-L-lactide) copolyesters with molar masses as high as $70000 \mathrm{~g} / \mathrm{mol}$. The maximum $\gamma \mathrm{BL}$ content obtained was around $17 \% .^{10,34}$ Cyclic tin alkoxide was also showing some activities to synthesize $\gamma$ BL-based copolymers with the same limitations. ${ }^{35}$

1-Ethoxy-3-chlorotetrabutyldistannoxane was able to copolymerize $\gamma \mathrm{BL}$ with $\beta$-butyrolactone $(\beta \mathrm{BL})$ at $100^{\circ} \mathrm{C}$ in bulk. ${ }^{36}$ The amount of $\gamma \mathrm{BL}$ in the copolymer is highly dependent on the monomer feed ratio going from $6 \%$ to $35 \%$ for a molar ratio of $\beta \mathrm{BL} / \gamma \mathrm{BL}$ going from $90 / 10$ to $10 / 90$ respectively. Number-average molar mass $\left(\overline{M_{n}}\right)$ and polymerization yields decreased from $96000 \mathrm{~g} / \mathrm{mol}$ and $96 \%$ to $2700 \mathrm{~g} / \mathrm{mol}$ and $13 \%$ with the increase of the amount of $\gamma \mathrm{BL}$ in the monomer feed (mol\%) from $10 \%$ to $90 \%$.

The samarium(II) aryloxide complex $\mathrm{Sm}(\mathrm{OAr})_{2}(\mathrm{THF}) 3^{37}$ or a samarium iodide based complex ${ }^{38}$ showed some activity for the ROCP of $\gamma \mathrm{BL}$ and $\varepsilon \mathrm{CL}$ at $20{ }^{\circ} \mathrm{C}$. The formation of $\varepsilon \mathrm{CL}-\gamma \mathrm{BL}$ copolymers without $\gamma \mathrm{BL}$ blocks and limited $\gamma \mathrm{BL}$ conversion were observed with this system. Similar conclusions were drawn when using an aluminum Schiff's base complex HAPENAIO ${ }^{i}$ Pr with calculated reactivity ratios equal to $r_{\varepsilon} \mathrm{CL}=19.4$ and $r_{\gamma \mathrm{BL}}=0.11$, confirming the presence of long sequence of $\varepsilon \mathrm{CL}$ units in the copolymer. ${ }^{27}$

The ROP of $\gamma \mathrm{BL}$ using $\mathrm{La}\left[\mathrm{N}\left(\mathrm{SiMe}_{3}\right)_{2}\right]_{3}$ alone was also shown to synthesize $\mathrm{P} \gamma \mathrm{BL}$ in a few percent yield when working at high monomer concentration and $-40{ }^{\circ} \mathrm{C}$ (Scheme 4). A typical coordination-insertion mechanism for chain initiation and propagation steps was proposed with the formation of linear and cyclic polymers due to intramolecular back-biting. ${ }^{18,28}$

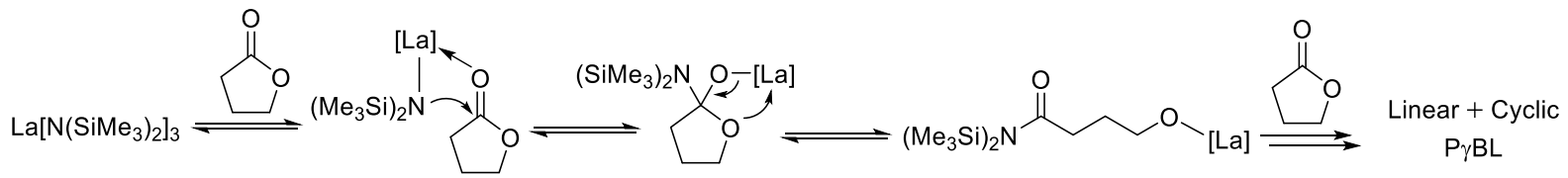

Scheme 4: Proposed mechanism for ROP of $\gamma \mathrm{BL}$ using $\mathrm{La}\left[\mathrm{N}\left(\mathrm{SiMe}_{3}\right)_{2}\right]_{3}{ }^{18}$

\section{Organic bases and acid-base pairs as initiators/catalysts}

Since the description in 2001 of the first nucleophilic organocatalyzed ROP of lactide ${ }^{39}$, lots of organocatalytic systems have been studied for the ROP of cyclic esters. ${ }^{40}$ The phosphazene base, 1-tert-butyl-4,4,4-tris(dimethylamino)-2,2-bis-[tris(dimethylamino)phosphoranylidenamino]$2 \lambda^{5}, 4 \lambda^{5}$-catenadi(phosphazene) $\left(t-\mathrm{BuP}_{4}\right)$ is one of them and is shown to achieve the synthesis of metal-free $\mathrm{P} \gamma \mathrm{BL} .{ }^{19}$ The polymerization is performed at high monomer concertation and low temperature $\left(-40{ }^{\circ} \mathrm{C}\right)$. Two different mechanisms are proposed by E. Chen and coworkers depending on the use of an alcohol as initiator or not. The superbase can directly initiate the polymerization by deprotonation of $\gamma \mathrm{BL}$ to generate a reactive enolate species. But the most efficient method is to deprotonate an alcohol such as $\mathrm{BnOH}$ by the organic base and get high molar mass polymers in high yields (Scheme 5). Linear and cyclic $\mathrm{P} \gamma \mathrm{BL}$ were obtained in both cases. ROCP of $\gamma \mathrm{BL}$ with $\varepsilon \mathrm{CL}$ and $\delta \mathrm{VL}$ following the same approach was also successful. ${ }^{28}$ 
Noteworthy, the organic catalyst system based on $t-\mathrm{BuP}_{4} / \mathrm{BnOH}$ afforded the copolyesters with high $\gamma \mathrm{BL}$ incorporation (42 to $80 \%$ ) at a relatively low $\gamma \mathrm{BL} / \varepsilon \mathrm{CL}$ feed ratio (3 or $4 / 1$ ).

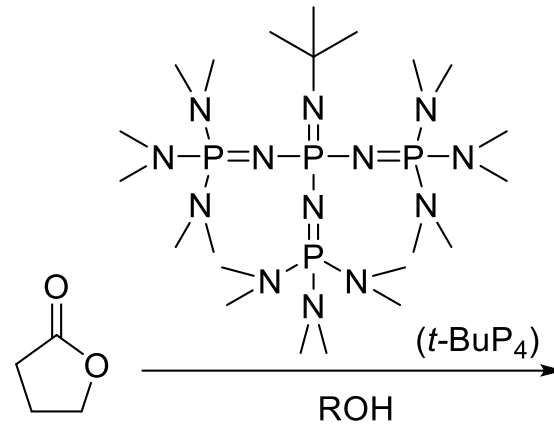

Scheme 5: $t$-BuP 4 /alcohol system as initiating species for ROP of $\gamma \mathrm{BL}^{19}$

Cyclic trimeric phosphazene base (CTPB, Scheme 6) was also proposed as an organocatalyst for ROP of $\gamma \mathrm{BL} .{ }^{20} \mathrm{CTPB}$ was said inactive in the absence of any alcohol whereas it serves as a highly efficient system in the presence of $\mathrm{BnOH}$ in toluene at $-60{ }^{\circ} \mathrm{C}$ to offer well-defined $\mathrm{P} \gamma \mathrm{BL}$ with high monomer conversion (up to $98 \%$ in 4 hours). The mechanism proposed is similar to the one involving $t$ - $\mathrm{BuP}_{4} / \mathrm{BnOH}$ initiating system (Scheme 5). The ion pair $\left[\mathrm{BnO}^{-\cdots} \cdot \mathrm{CTPBH}^{+}\right]$ can polymerize $\gamma \mathrm{BL}$ and the bulky counter-ion seems to prevent the back-biting reaction and therefore producing only $\mathrm{P} \gamma \mathrm{BL}$ with linear structures. In comparison with alkali metal alkoxides discussed previously, this system showed a better efficiency probably due to its improved solubility in the reaction medium. Block copolymers of $\gamma \mathrm{BL}$ and L-lactide (LLA) were prepared with the same phosphazene base via sequential ROP of $\gamma \mathrm{BL}$ and LLA. ${ }^{41}$

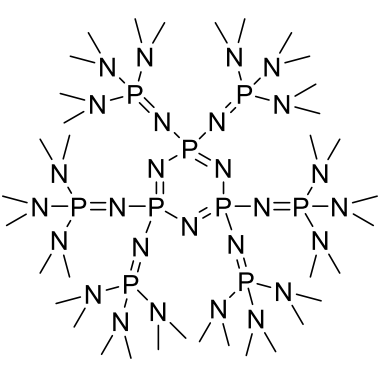

Scheme 6: Cyclic trimeric phosphazene base (CTPB) for ROP/ROCP of $\gamma \mathrm{BL}^{20,25,26}$

CTPB/ureas binary organocatalysts were also studied for the ROP of $\gamma \mathrm{BL}^{25}$. Using 1cyclohexyl-3-(4-methoxyphenyl) urea, a urea bearing unsymmetrical and electron-donating substituents (Scheme 7), P $\gamma$ BL contained linear and cyclic structures with $\overline{M_{n}}$ up to 35000 $\mathrm{g} / \mathrm{mol}$, four times higher than CTPB alone, was prepared. The mechanism involved is similar to the one described for alkali metal alkoxide / urea systems (Scheme 1).

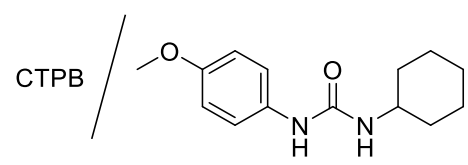




\section{Scheme 7: CTPB/urea system used for ROP of $\gamma \mathrm{BL}^{25}$}

A dual organocatalysts based on the combination of $t-\mathrm{BuP}_{4}$ and symmetrical thioureas bearing electron-donating groups was also demonstrated as an efficient organocatalytic system to synthesize linear $\mathrm{P} \gamma \mathrm{BL}$ with high polymerization rates (up to $80 \%$ monomer conversion in 4 hours) at low temperature (Scheme 8$){ }^{22}$

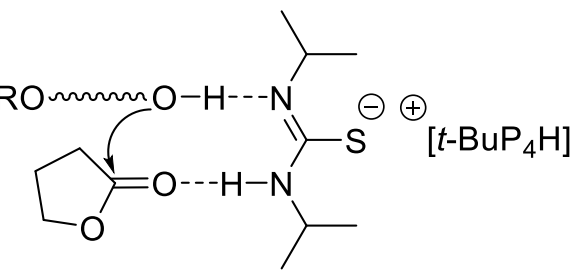

Scheme 8: $t$-BuP 4 /thiourea system for the ROP of $\gamma \mathrm{BL}^{22}$

$N$-heterocyclic olefins (NHOs) were also recently used for the polymerization of $\gamma \mathrm{BL}$ in bulk at $-36{ }^{\circ} \mathrm{C}$. Polyesters with a mixture of cyclic and linear structures were obtained only when an initiator $(\mathrm{BnOH})$ was initially added, meaning that a zwitterionic polymerization cannot occur. ${ }^{21} 70 \%$ monomer conversion could be reached after 2 days and polymers with $\overline{M_{n}}$ up to $7000 \mathrm{~g} / \mathrm{mol}$ with a dispersity around 1.8 were observed. The addition of a Lewis acid such as lithium halides (LiX) was shown to retard/decrease the backbiting reaction by transesterification and therefore the formation of macrocycle polymers. Random copolyesters (with $\omega$-pentadecalactone, $\varepsilon \mathrm{CL}$ and $\delta \mathrm{VL}$ as comonomer) could also be prepared at low polymerization temperature in the presence of an alcohol as initiator with a $\gamma \mathrm{BL}$ content in copolymers reaching $22 \%{ }^{42}$

Interestingly, the polymerization could occurred also without any alcohol but only in the presence of a highly nucleophilic NHO, in agreement with a zwitterionic mechanism (Scheme 9). ${ }^{21}$ In the absence of any initiator, one can note that the enolization of the lactone is favored over nucleophilic ring-opening when a sterically hindered but strongly basic NHOs is used. The typical anionic polymerization mechanism observed was proposed (Scheme 10). ${ }^{21}$

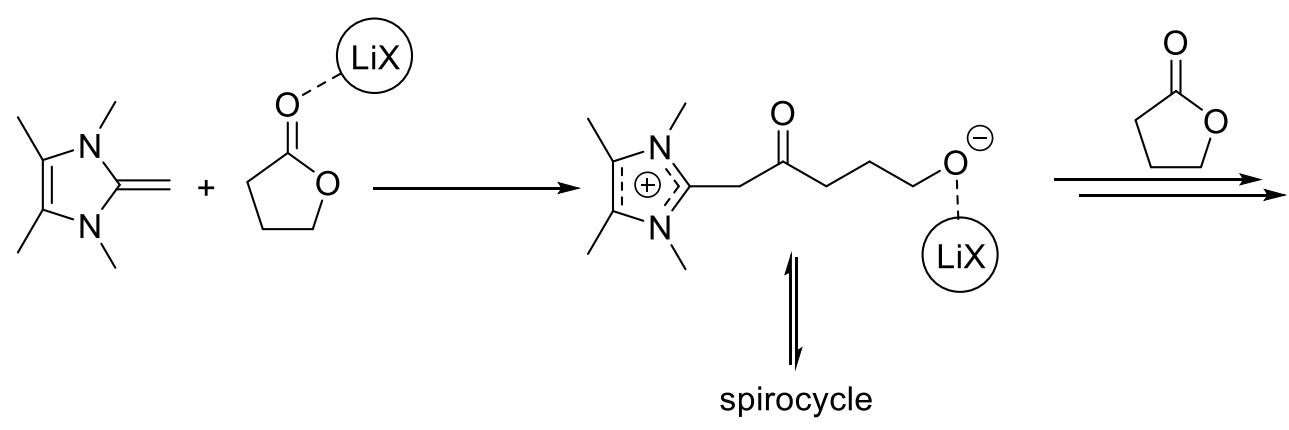

Scheme 9: Zwitterionic ROP of $\gamma$ BL by NHOs/LiX system ${ }^{21}$ 


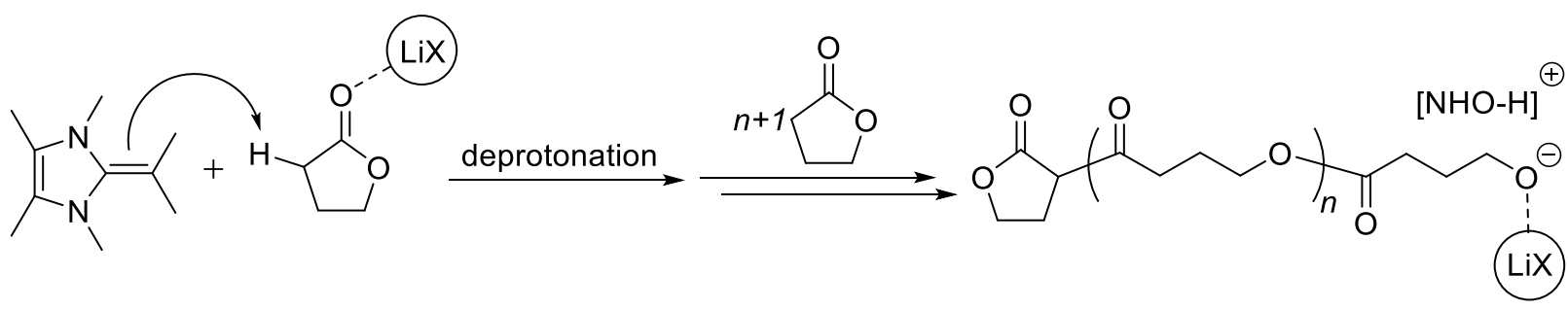

Scheme 10: Deprotonation and ROP of $\gamma \mathrm{BL}$ by strongly basic NHO/LiX ${ }^{21}$

\section{$4 \quad$ Lewis acids and Brønsted acids}

Cationic ROCP of $\gamma \mathrm{BL}$ was far less studied than anionic or coordination-insertion polymerization. Nevertheless, the first paper dealing with cationic ROP of $\gamma$ BL was published in $1951 .{ }^{43}$ Indeed, Meerwein used tertiary oxonium salts (based on boron Lewis acids) to produce merely dimers and trimers.

Later, triethylaluminium associated to water $\left(\mathrm{AlEt}_{3}-\mathrm{H}_{2} \mathrm{O}\right)$ revealed an effective catalytic system for the copolymerization of $\gamma \mathrm{BL}$ and $\beta \mathrm{PL}$, whereas diethylzinc associated to water $\left(\mathrm{ZnEt}_{2}-\mathrm{H}_{2} \mathrm{O}\right)$ was only able to achieve the homopolymerization of $\beta$ PL. ${ }^{29} \mathrm{Up}$ to $29.5 \%$ of $\gamma \mathrm{BL}$ could be incorporated and reactivity ratios were determined to be $\mathrm{r}_{\gamma \mathrm{BL}}=0.36$ and $\mathrm{r}_{\beta \mathrm{PL}}=18$.

Copolymerization of 3,3-Bis(chloromethyl)oxetane (BCMO) and $\gamma \mathrm{BL}$ were performed in toluene at room temperature with Tin(IV) chloride $\left(\mathrm{SnCl}_{4}\right)$ and $\mathrm{BF}_{3} \cdot \mathrm{Et}_{2} \mathrm{O}{ }^{44}$ Alternating copolymers with low yield were produced. This is the only paper about copolymerization of $\gamma \mathrm{BL}$ and cyclic ether as cyclic lactones are usually used as comonomer.

In the $80 \mathrm{~s}$, Kricheldorf showed that iron(III) chloride $\left(\mathrm{FeCl}_{3}\right)$, aluminium (III) chloride $\left(\mathrm{AlCl}_{3}\right)$ $\mathrm{BF}_{3} \cdot \mathrm{Et}_{2} \mathrm{O}$ and fluorosulfonic acid $\left(\mathrm{FSO}_{3} \mathrm{H}\right)$ were able to catalyze the random copolymerization of $\gamma \mathrm{BL}$ and glycolide at $60{ }^{\circ} \mathrm{C}$ in bulk with an incorporation of $\gamma \mathrm{BL}$ up to $30 \%$ with $\mathrm{FeCl}_{3}$ (Scheme 11). ${ }^{30}$ It was also shown that an increase of the amount of $\gamma \mathrm{BL}$ in the monomer feed decreased significantly the polymerization yield. On the contrary, $\mathrm{ZnCl}_{2}, \mathrm{Al}\left(\mathrm{O}^{i} \mathrm{Pr}\right)_{3}$ and dibutyldimethoxytin $\left(n \mathrm{Bu}_{2} \mathrm{Sn}(\mathrm{OMe})_{2}\right)$ were only able to achieve the homopolymerization of glycolide.

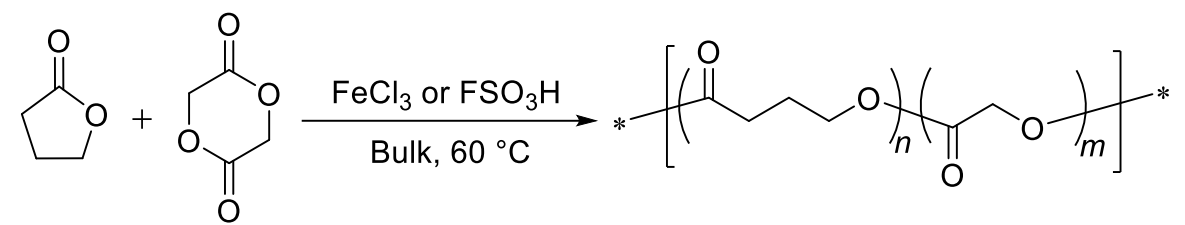

Scheme 11: Acid-catalyzed ROCP of $\gamma \mathrm{BL}$ and glycolide ${ }^{30}$

Copolymerization of $\gamma \mathrm{BL}$ and $\beta \mathrm{BL}$ has been performed with boron trifluoride diethyl etherate $\left(\mathrm{BF}_{3} \bullet \mathrm{Et}_{2} \mathrm{O}\right)$, trifluoromethanesulfonic acid $\left(\mathrm{CF}_{3} \mathrm{SO}_{3} \mathrm{H}\right)$ or methyl trifluoromethanesulfonate in bulk at room temperature for 7 days, whereas $\mathrm{AlCl}_{3}$ and antimony(III) fluoride $\left(\mathrm{SbF}_{3}\right)$ were shown to be ineffective (Scheme 12). ${ }^{45}$ Combination of $\gamma \mathrm{BL}$ and $\beta \mathrm{BL}$ leads to the random $\operatorname{poly}(\gamma \mathrm{BL}-c o-\beta \mathrm{BL})\left(\overline{M_{n}}=1800-4400 \mathrm{~g} / \mathrm{mol}, \emptyset=1.3-1.8\right)$ whose structure is identical to that of poly(hydroxy alkanoate)s produced by micro-organisms. With $\mathrm{BF}_{3} \bullet \mathrm{Et}_{2} \mathrm{O}$, the incorporation of 
$\gamma \mathrm{BL}$ increases with the feed ratio $(\gamma \mathrm{BL} / \beta \mathrm{BL})$ and reaches $56 \%$ at a molar ratio of $90 / 10$ $(\gamma \mathrm{BL} / \beta \mathrm{BL})$. Determined reactivity ratios were equal to $\mathrm{r}_{\gamma \mathrm{BL}}=0.48$ and $\mathrm{r}_{\beta \mathrm{BL}}=0.58$. It is proposed that adventitious water contained in the reaction medium served as the initiator by reacting with $\mathrm{BF}_{3}$-activated monomers. Lauryl alcohol was also used as an initiator.

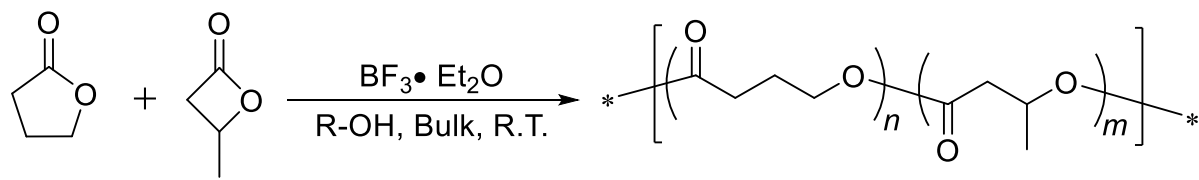

Scheme 12: Lewis acid-catalyzed ROCP of $\gamma \mathrm{BL}$ and $\beta \mathrm{BL}^{45}$

$\mathrm{CF}_{3} \mathrm{SO}_{3} \mathrm{H}$ was also shown to catalyze the ROP of $\gamma \mathrm{BL}$ initiated by methanol under high pressure $(800-1000 \mathrm{MPa})$ at $40{ }^{\circ} \mathrm{C} .{ }^{46}$ The $\overline{M_{n}}$ of obtained $\mathrm{P} \gamma \mathrm{BL}$ were in the range of $6000-8000 \mathrm{~g} / \mathrm{mol}$ $(Đ \approx 1.5)$. Scandium trifluoromethanesulfonate revealed also able to catalyze the homopolymerization of $\gamma \mathrm{BL}$ in similar conditions.

Copolymers of $\gamma \mathrm{BL}$ and $\varepsilon \mathrm{CL}$ have been synthesized with phosphoric acid at $200{ }^{\circ} \mathrm{C}$ after 3 days. Semi-crystalline copolymers $\left(\overline{M_{n}}=17800 \mathrm{~g} / \mathrm{mol}\right)$ with a melting temperature of $48{ }^{\circ} \mathrm{C}$ was obtained..$^{47}$

\section{5 enzymatic-catalyzed ROP of $\gamma \mathrm{BL}$}

More than 20 years ago, lipases have also been employed as catalysts for the ROP of $\gamma \mathrm{BL}$. For instance, $\mathrm{P} \gamma \mathrm{BL}$ has been obtained with Porcine Pancreatic lipase or lipase PS30 from pseudomonas cepacia after 18 days at $60{ }^{\circ} \mathrm{C}$ with a degree of polymerization $(D P)$ around $10 . .^{48}$ Copolymers with $\varepsilon \mathrm{CL}$ were also prepared with nevertheless a low incorporation of $\gamma \mathrm{BL} .{ }^{49}$ More recently, the use of immobilized lipase $\mathrm{B}$ from candida Antarctica in ionic liquids has led to the oligomerization of $\gamma \mathrm{BL}(D P=5) .{ }^{50}$

\section{Miscellaneous catalytic systems}

Tin(IV) ion-exchanged montmorillonite has been used for the polymerization of $\gamma \mathrm{BL}$ and its copolymerization with $\delta \mathrm{VL}$ at room temperature. For the homopolymerization, dimers and trimers were mainly obtained. For the copolymerization, DP around 4-6 were obtained with a low incorporation of $\gamma \mathrm{BL}$. ${ }^{51}$

The copolymerization of $\gamma \mathrm{BL}$ with (di)ethylene glycol catalyzed by activated clay in xylene at reflux was also studied. Oligomers were obtained and served as precursors for polyurethane synthesis. $^{52}$

It was also shown that even in the absence of any catalyst, it was possible to copolymerize $\gamma \mathrm{BL}$ with L-lactic acid or glycolic acid at $200{ }^{\circ} \mathrm{C}$ in bulk. ${ }^{53,54}$ Molar masses were below $2500 \mathrm{~g} / \mathrm{mol}$ for L-lactic acid and below $5200 \mathrm{~g} / \mathrm{mol}$ for glycolic acid with 10 to $20 \%$ of $\gamma \mathrm{BL}$ incorporated in the copolymer.

\section{CONCLUSION}


2 The ROP of $\gamma \mathrm{BL}$ has been considered for a long time to be impossible or hardly possible. 3 Nevertheless, it is reported in this review the recent progress that allow to control its ROP 4 process to yield $\mathrm{P} \gamma \mathrm{BL}$ with high molar mass especially with alkali metal alkoxide / urea systems 5 in relatively mild reaction conditions. Anionic and coordination-insertion polymerizations have 6 been more studied than cationic ones. Low reaction temperatures remain compulsory to perform 7 the homopolymerization of $\gamma \mathrm{BL}$ as well as high initial monomer concentration.

8 The ROCP of $\gamma \mathrm{BL}$ with other cyclic esters has been more studied than its homopolymerization. 9 In this case, it was shown that $\gamma \mathrm{BL}$ could be incorporated even if the polymerization was not 10 performed at low temperature. 


\section{REFERENCES}

1. Longo JM, Sanford MJ, Coates GW. Ring-Opening Copolymerization of Epoxides and Cyclic Anhydrides with Discrete Metal Complexes: Structure-Property Relationships. Chem Rev. 2016.

2. Hillmyer MA, Tolman WB. Aliphatic polyester block polymers: renewable, degradable, and sustainable. Acc Chem Res. 2014;47(8):2390-2396.

3. Schneiderman DK, Hillmyer MA. Aliphatic Polyester Block Polymer Design. Macromolecules. 2016;49(7):2419-2428.

4. Gonçalves FAMM, Fonseca AC, Domingos M, Gloria A, Serra AC, Coelho JFJ. The potential of unsaturated polyesters in biomedicine and tissue engineering: Synthesis, structureproperties relationships and additive manufacturing. Prog Polym Sci. 2017;68:1-34.

5. Kamber NE, Jeong W, Waymouth RM, Pratt RC, Lohmeijer BG, Hedrick JL. Organocatalytic ring-opening polymerization. Chem Rev. 2007;107(12):5813-5840.

6. Penczek S, Cypryk M, Duda A, Kubisa P, Slomkowski S. Living ring-opening polymerizations of heterocyclic monomers. Prog Polym Sci. 2007;32(2):247-282.

7. Jerome $C$, Lecomte P. Recent advances in the synthesis of aliphatic polyesters by ringopening polymerization. Adv Drug Deliv Rev. 2008;60(9):1056-1076.

8. Hu S, Zhao J, Zhang G, Schlaad H. Macromolecular architectures through organocatalysis. Prog Polym Sci. 2017;74:34-77.

9. Moore T, Adhikari R, Gunatillake P. Chemosynthesis of bioresorbable poly(gammabutyrolactone) by ring-opening polymerisation: a review. Biomaterials. 2005;26(18):37713782.

10. Nakayama A, Kawasaki N, Aiba S, Maeda Y, Arvanitoyannis I, Yamamoto N. Synthesis and biodegradability of novel copolyesters containg $\mathrm{\gamma}$-butyrolactone units. Polymer. 1998;39(5):1213-1222.

11. Houk K, Jabbari A, Hall $\mathrm{H}$, Alemán $\mathrm{C}$. Why $\delta$-valerolactone polymerizes and $\mathrm{\gamma}$-butyrolactone does not. J Org Chem. 2008;73(7):2674-2678.

12. Dubois P, Coulembier O, Raquez J-M. Handbook of Ring-Opening Polymerization. 2009.

13. Aleman C, Betran O, Casanovas J, Houk KN, Hall HK, Jr. Thermodynamic control of the polymerizability of five-, six-, and seven-membered lactones. J Org Chem. 2009;74(16):62376244.

14. Saiyasombat W, Molloy R, Nicholson TM, Johnson AF, Ward IM, Poshyachinda S. Ring strain and polymerizability of cyclic esters. Polymer. 1998;39(23):5581-5585.

15. Carothers WH, Dorough GL, Natta FJv. Studies of Polymerization and Ring Formation. X. The Reversible Polymerization of Six-Membered Cyclic Esters. J Am Chem Soc. 1932;54(2):761772.

16. Hall HK, Schneider AK. Polymerization of Cyclic Esters, Urethans, Ureas and Imides. J Am Chem Soc. 1958;80(23):6409-6412.

17. Korte F, Glet W. Hochdruckreaktionen. II. Die polymerisation von $\gamma$-Butyrolacton und $\delta$ Valerolactam bei hohen drücken. Journal of Polymer Science Part B: Polymer Letters. 1966;4(10):685-689.

18. Hong M, Chen EY. Completely recyclable biopolymers with linear and cyclic topologies via ring-opening polymerization of gamma-butyrolactone. Nat Chem. 2016;8(1):42-49.

19. Hong M, Chen EY. Towards Truly Sustainable Polymers: A Metal-Free Recyclable Polyester from Biorenewable Non-Strained gamma-Butyrolactone. Angew Chem Int Ed Engl. 2016;55(13):4188-4193.

20. Zhao N, Ren C, Li H, Li Y, Liu S, Li Z. Selective Ring-Opening Polymerization of Non-Strained gamma-Butyrolactone Catalyzed by A Cyclic Trimeric Phosphazene Base. Angew Chem Int Ed Engl. 2017;56(42):12987-12990.

21. Walther P, Frey W, Naumann S. Polarized olefins as enabling (co)catalysts for the polymerization of $\gamma$-butyrolactone. Polym Chem. 2018;9(26):3674-3683. 
22. Zhang C-J, Hu L-F, Wu H-L, Cao X-H, Zhang X-H. Dual Organocatalysts for Highly Active and Selective Synthesis of Linear Poly $(\gamma$-butyrolactone)s with High Molecular Weights. Macromolecules. 2018;51(21):8705-8711.

23. Lin L, Han D, Qin J, et al. Nonstrained $\gamma$-Butyrolactone to High-Molecular-Weight Poly( $\gamma$ butyrolactone): Facile Bulk Polymerization Using Economical Ureas/Alkoxides. Macromolecules. 2018;51(22):9317-9322.

24. Olsen P, Odelius K, Albertsson AC. Thermodynamic Presynthetic Considerations for RingOpening Polymerization. Biomacromolecules. 2016;17(3):699-709.

25. Shen Y, Zhao Z, Li Y, Liu S, Liu F, Li Z. A facile method to prepare high molecular weight biorenewable poly( $\gamma$-butyrolactone) using a strong base/urea binary synergistic catalytic system. Polym Chem. 2019;10(10):1231-1237.

26. Shen Y, Zhang J, Zhao Z, Zhao N, Liu F, Li Z. Preparation of Amphiphilic Poly(ethylene glycol)b-poly(gamma-butyrolactone) Diblock Copolymer via Ring Opening Polymerization Catalyzed by a Cyclic Trimeric Phosphazene Base or Alkali Alkoxide. Biomacromolecules. 2019;20(1):141-148.

27. Bhaw-Luximon A, Jhurry D, Motala-Timol S, Lochee Y. Polymerization of $\varepsilon$-Caprolactone and its Copolymerization with $\gamma$-Butyrolactone using Metal Complexes. Macromolecular Symposia. 2005;231(1):60-68.

28. Hong M, Tang X, Newell BS, Chen EYX. "Nonstrained" $\gamma$-Butyrolactone-Based Copolyesters: Copolymerization Characteristics and Composition-Dependent (Thermal, Eutectic, Cocrystallization, and Degradation) Properties. Macromolecules. 2017;50(21):8469-8479.

29. Tada K, Numata $Y$, Saegusa T, Furukawa J. Copolymerization of $\gamma$-butyrolactone and $\beta$ propiolactone. Makromol Chem. 1964;77(1):220-228.

30. Kricheldorf HR, Mang T, Jonté JM. Polylactones, 2 Copolymerization of glycolide with $\beta$ propiolactone, $\gamma$-butyrolactone or $\delta$-valerolactone. Makromol Chem. 1985;186(5):955-976.

31. Duda A, Penczek $S$, Dubois $P$, Mecerreyes $D$, Jérôme R. Oligomerization and copolymerization of $\gamma$-butyrolactone - a monomer known as unable to homopolymerize, 1 . Copolymerization with ع-caprolactone. Macromol Chem Phys. 1996;197(4):1273-1283.

32. Duda A, Biela T, Libiszowski J, et al. Block and random copolymers of $\varepsilon$-caprolactone. Polym Degrad Stab. 1998;59(1-3):215-222.

33. Duda A, Libiszowski J, Mosnáček J, Penczek S. Copolymerization of Cyclic Esters at the Living Polymer-Monomer Equilibrium. Macromolecular Symposia. 2005;226(1):109-120.

34. Nakayama A, Kawasaki N, Arvanitoyannis I, Aiba S, Yamamoto N. Synthesis and biodegradation of poly( $\gamma$-butyrolactone-co-I-lactide). Journal of Environmental Polymer Degradation. 1996;4(3):205-211.

35. Wei Z, Liu L, Qi M. Synthesis and characterization of homo- and co-polymers of (R,S)- $\beta$ butyrolactone and $\gamma$-butyrolactone or $\beta$-valerolactone initiated with cyclic tin alkoxide. React Funct Polym. 2006;66(12):1411-1419.

36. Hori Y, Yamaguchi A, Hagiwara T. Chemical synthesis of high molecular weight poly(3hydroxybutyrate-co-4-hydroxybutyrate). Polymer. 1995;36(24):4703-4705.

37. Nishiura M, Hou Z, Koizumi T-a, Imamoto T, Wakatsuki Y. Ring-Opening Polymerization and Copolymerization of Lactones by Samarium(II) Aryloxide Complexes. Macromolecules. 1999;32(25):8245-8251.

38. Agarwal S, Xie X. SmI2/Sm-Based $\psi$-Buyrolactone- $\varepsilon$-Caprolactone Copolymers: Microstructural Characterization Using One- and Two-Dimensional NMR Spectroscopy. Macromolecules. 2003;36(10):3545-3549.

39. Nederberg F, Connor, EF., Möller, M., Glauser, T., Hedrick, JL. . New paradigms for organic catalysts: the first organocatalytic living polymerization. Angew Chem Int Ed Engl. 2001;40:2712-2715.

40. Carlotti S, Peruch F. . Cyclic Monomers: Epoxides, Lactide, Lactones, Lactams, Cyclic Siliconcontaining monomers, Cyclic Carbonates and others. In: Hadjichristidis N, Hirao, A. , ed. 
Anionic Polymerization: Principles, Practice, Strength, Consequences, and Applications. Springer of Japan; 2015:191-305.

41. Shen Y, Zhang J, Zhao N, Liu F, Li Z. Preparation of biorenewable poly( $\gamma$-butyrolactone)-bpoly(I-lactide) diblock copolyesters via one-pot sequential metal-free ring-opening polymerization. Polym Chem. 2018;9(21):2936-2941.

42. Walther P, Naumann S. N-Heterocyclic Olefin-Based (Co)polymerization of a Challenging Monomer: Homopolymerization of $\omega$-Pentadecalactone and Its Copolymers with $\psi$ Butyrolactone, $\delta$-Valerolactone, and $\varepsilon$-Caprolactone. Macromolecules. 2017;50(21):84068416.

43. Meerwein H. Uber oxoniumverbindungen des Säure-ester und lactone. Angew Chem. 1951;63(20):480-481.

44. Ito K, Inoue T, Yamashita Y. Copolymerizations of 3.3-bis(chloromethyl)oxacyclobutane with $\beta$-propiolactone and $\gamma$-butyrolactone by lewis acids: "Two-state" polymerization mechanism. Makromol Chem. 1970;139(1):153-164.

45. Lee CW, Urakawa R, Kimura Y. Copolymerization of $\gamma$-butyrolactone and $\beta$-butyrolactone. Macromol Chem Phys. 1997;198(4):1109-1120.

46. Yamashita K, Yamamoto K, Kadokawa J-i. Acid-catalyzed Ring-opening Polymerization of $\gamma^{-}$ Butyrolactone under High-pressure Conditions. Chem Lett. 2014;43(2):213-215.

47. Lin WJ. Comparison of thermal characteristics and degradation properties of epsiloncaprolactone copolymers. J Biomed Mater Res. 1999;47(3):420-423.

48. Nobes GAR, Kazlauskas RJ, Marchessault RH. Lipase-Catalyzed Ring-Opening Polymerization of Lactones: A Novel Route to Poly(hydroxyalkanoate)s. Macromolecules. 1996;29(14):48294833.

49. Dong H, Wang H-d, Cao S-g, Shen J-c. Lipase-catalyzed polymerization of lactones and linear hydroxyesters. Biotechnol Lett. 1998;20(10):905-908.

50. Gorke JT, Okrasa K, Louwagie A, Kazlauskas RJ, Srienc F. Enzymatic synthesis of poly(hydroxyalkanoates) in ionic liquids. J Biotechnol. 2007;132(3):306-313.

51. Kadokawa J, Iwasaki Y, Tagaya H. Ring-opening polymerization of lactones catalyzed by ionexchanged clay montmorillonite. Green Chem. 2002;4(1):14-16.

52. Miura H, Tajima T, Nagata M, Royama T, Saito K, Hasegawa M. Synthesis of Poly(ester ether)s by the Reaction of .GAMMA.-Butyrolactone with Diols and Their Application to Polyurthaues. Kobunshi Ronbunshu. 1999;56(5):291-297.

53. Fukuzaki H, Aiba Y, Yoshida M, Asano M, Kumakura M. Direct copolymerization of L-lactic acid with $\gamma$-butyrolactone in the absence of catalysts. Die Makromolekulare Chemie. 1989;190(7):1553-1559.

54. Fukuzaki H, Yoshida M, Asano M, Aiba Y, Kumakura M. Direct copolymerization of glycolic acid with lactones in the absence of catalysts. European Polymer Journal. 1990;26(4):457461. 